\section{Policy Research Working Paper \\ Identifying Welfare Effects from Subjective Questions}

Martin Ravallion

Michael Lokshin

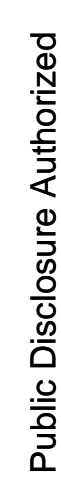

The World Bank

Development Research Group

Poverty and Human Resources

March 2000

\section{WPS 2301}

2301
In subjective surveys, people who become ill or lose their jobs report reduced welt being, even if they later get a job. Perhaps their exposure to uninsured risk outside the formal employment sector reduces their expectations about future income. Do potential biases cloud the inferences that can be drawn from subjective surveys? 
Policy Research Working Paper 2301

\section{Summary findings}

Ravallion and Lokshin argue that the welfare inferences drawn from subjective answers to questions on qualitative surveys are clouded by concerns about the structure of measurement errors and how latent psychological factors influence observed respondent characteristics.

They propose a panel data model that allows more robust tests. In applying the model to high-quality panel data for Russia for 1994-96, they find that some results widely reported in past studies of subjective well-being appear to be robust but others do not.

Household income, for example, is a highly significant predictor of self-rated economic welfare; per capita income is a weaker predictor.
Ill health and loss of a job reduce self-reported economic welfare, but demographic effects are weak at a given current income.

And the effect of unemployment is not robust. Returning to work does not restore a sense of welfare unless there is an income gain. The results imply that even transient unemployment brings the feeling of a permanent welfare loss, suggesting that high unemployment benefits do not attract people out of work but do discourage a return to work.

This paper - a product of Poverty and Human Resources, Development Research Group - is part of a larger effort in the group to understand the relationship between subjective and objective economic welfare. Copies of the paper are available free from the World Bank, 1818 H Street NW, Washington, DC 20433. Please contact Patricia Sader, room MC3-556, telephone 202-473-3902, fax 202-522-1153, email address psader@worldbank.org. Policy Research Working Papers are also posted on the Web at www.worldbank.org/research/workingpapers. The authors may be contacted at mravallion@worldbank.org and mlokshin@worldbank.org. March 2000.(37 pages)

The Policy Research Working Paper Series disseminates the findings of work in progress to encourage the exchange of ideas about development issues. An objective of the series is to get the findings out quickly, even if the presentations are less than fully polished. The papers carry the names of the authors and should be cited accordingly. The findings, interpretations, and conclusions expressed in this paper are entirely those of the authors. They do not necessarily represent the view of the World Bank, its Executive Directors, or the countries they represent. 


\title{
Identifying Welfare Effects from Subjective Questions
}

\author{
Martin Ravallion and Michael Lokshin ${ }^{1}$ \\ World Bank, 1818 H Street NW, Washington DC
}

Key words: Subjective wellbeing, income, unemployment, personality, Russia, panel data JEL classifications: D 60, I31

Word count: 9862

1 Address for correspondence (1999-2000): Martin Ravallion, ARQADE, University of Toulouse 1, Manufacture des Tabacs, 21 Allee de Brienne, 31000 Toulouse, France. The financial support of the World Bank's Research Committee (under RPO 681-39) is gratefully acknowledged. The findings, interpretations, and conclusions of this paper are those of the authors, and should not be attributed to the World Bank, its Executive Directors, or the countries they represent. The authors are grateful to Dominique van de Walle and seminar participants at the World Bank for helpful comments. 



\section{Introduction}

A large literature in economics and psychology has sought to understand why some people purport to feel well off in interviews, while others do not. Answers have been sought in respondents' objective economic circumstances. And conclusions have been drawn about the welfare effects of changes in (for example) incomes, employment and household size.

The results have typically suggested that incomes do not have much power to explain perceived welfare. Substantial economic growth since the 1950 s did not bring higher average self-rated happiness in either the U.S. (Easterlin, 1974, 1995; Diener et al., 1999) or Japan (Veenhoven et al., 1993). Cross-sectional micro data often suggest a positive correlation with individual or household incomes, but it is generally not what one would call a strong correlation; DeNeve and Cooper (1998) quote a mean correlation coefficient between income and subjective wellbeing of 0.17 (over 85 independent samples). ${ }^{2}$

These studies have used broad welfare concepts ("happiness" or "satisfaction with life") that undoubtedly embrace much more than command over market goods. One might conjucture that focusing on the narrower idea of "economic welfare" or "poverty" would reveal a far stronger relationship with income. We can offer two observations suggesting that it does not; one is from aggregate data and the other from micro data:

(i) A well-known example of a self-rated poverty measure is that used in the surveys done by the Social Weather Station (SWS) in the Philippines. Respondents in regular surveys are asked whether they are "poor", "borderline" or "non-poor". From the SWS data presented in Mangahas (1995), it appears that growth in GDP per capita in the Philippines has been associated with a rising proportion of the population saying they are "poor".

(ii) In the main surveys for Russia we use later, respondents rated their economic welfare on a nine-rung ladder from "poor" to "rich". The correlation coefficients with

2 Surveys of the literature can be found in Argyle (1987), Diener (1984, 1994), Furnham and Argyle (1998, Chapter 11) and Diener et al., (1999). 
household income per person are 0.11 for 1994 and 0.20 for 1996 . Though both are highly significant by a conventional test, ${ }^{3}$ they are not any higher than the correlations found with more holistic concepts of "happiness" or "life satisfaction".

In attempting to explain observations such as these it has been argued that it may in fact be relative income - relative to some reference group - that drives self-rated welfare, rather than absolute income. This is the now classic interpretation that Easterlin (1974) offered for the fact that aggregate happiness has responded so little to economic growth in the U.S. even though income and subjective wellbeing are correlated (albeit weakly) across people at one date. ${ }^{4}$ Similarly, respondents to the SWS question on subjective poverty may well be strongly influenced by their perceived income relative to (say) the mean at each survey date. By this view, absolute incomes that are shared with all those in the relevant reference group do not raise perceived wellbeing.

Another respondent characteristic widely identified as important is unemployment. A number of papers have found that the unemployed have lower self-rated welfare with and without controls for income. ${ }^{5}$ The adverse effect of unemployment at given income appears to contradict the prediction of the standard economic model of work-leisure choice that unemployment (and hence greater leisure) is desirable at given income. Implications have been drawn for policy discussions of the supposed disincentive effect of unemployment compensation (see, for example, Blanchflower and Oswald, 1997).

Evidence has also been found of strong demographic effects on subjective welfare (such as household size, stage of the life-cycle, and marital status) and of effects of health status; for a recent survey of the socioeconomic correlates of subjective wellbeing see Diener

3 The t-ratios are 7.70 and 14.95 respectively with sample sizes of about 5400 , though such tests ignore the discrete ordinal nature of the subjective welfare data.

4 Reference group effects have been discussed by (inter alia) Runciman (1966), Easterlin (1974, 1995), Frank (1985), van de Stadt et al., (1985) and Clark and Oswald (1996).

5 Examples include Clark and Oswald (1994), Blanchflower (1996), Blanchflower and Oswald (1997) and Winkelmann and Winkelmann (1998). 
et al., (1999). A number of these welfare effects are hard to identify otherwise (see, for example, Lanjouw and Ravallion, 1995, on identifying the individual welfare effect of household size.)

This paper identifies a number of problems that cloud the inferences that can be drawn from survey responses on subjective welfare. We draw on research in psychology suggesting that relatively stable personality traits influence how people respond to subjective welfare questions. Just as any welfare comparison requires a consistent preference ordering, identifying welfare effects in subjective data requires that we control for these latent psychological differences. We argue that failure to control for latent heterogeneity also biases welfare inferences at given tastes, since there is also evidence (mostly from psychology) that these same differences influence socioeconomic characteristics. We also point to a number of other potential biases in interpreting subjective data, such as related to the likely structure of measurement errors.

We then propose and implement an approach that is likely to be more robust to the main problems identified. We use a comprehensive multi-purpose panel survey for Russia that also included the question on subjective economic welfare mentioned above. The income measure from these surveys is built up from a detailed questionnaire and so is undoubtedly more reliable than measures commonly found in the literature on subjective welfare, which are often based on a single question, "what is your income?" The fact that the survey is longitudinal (re-surveying the same individuals over time) allows us to control for individual differences in personality that influence subjective welfare and are also likely to influence incomes, employment and other individual and household characteristics. In particular, we treat these effects as an idiosyncratic, time-invariant, error component correlated with the socioeconomic characteristics of respondents. Our model specification also incorporates other 
features of subjective welfare data suggested in the literature, notably that the data are qualitative, and that reference-group effects can generate non-constant parameters over time. This is not the first use of panel data to study subjective welfare. ${ }^{6}$ The two closest antecedents are van de Stadt et al., (1985) and Winkelmann and Winkelmann (1998). The former paper used panel data,in modeling a money metric of subjective welfare in the Netherlands. In addition to the difference in the dependent variable (which we explain later), van de Stadt et al., do not allow for latent individual effects. They do, however, allow for dynamics, by including the lagged subjective welfare measure as a regressor (though they cannot reject the null that its coefficient is unity). The paper by Winkelmann and Winkelmann is our closest antecedent. Importantly, we believe, the authors allow for a latent individual effect when modeling satisfaction with life in Germany. In addition to exploring a similar question in different data, we depart from the methods of Winkelmann and Winkelmann in a number of ways. One difference is that we focus on subjective economic welfare, rather than the seemingly broader — but also more ambiguous - concept of "satisfaction with life" that Winkelmann and Winkelmann use (in keeping with much of the literature). We focus on the more narrow concept in the expectation that it will offer sharper results on the welfare effects of economic variables; yes, "money does not buy you happiness", but surely it makes you think you are less poor? We also use a better income measure, built up from a detailed survey. Another difference is that we allow for time varying coefficients due to reference group effects. And we propose an estimation method for this type of qualitative data that does not require artificially collapsing the subjective welfare responses into a binary variable, as in Winkelmann and Winkelmann. ${ }^{7}$

6 In an earlier paper, we study the determinants of subjective welfare in Russia (Ravallion and Lokshin, 1998), but we do not allow for individual effects due to latent psychological factors.

7 Winkelmann and Winkelmann had to collapse the 10 rung welfare ladder in their survey into a binary variable so as to able to apply the Chamberlain's (1984) fixed effects logit model. 
The following section surveys past work. Section 3 describes the setting of our data. Descriptive results can be found in section 4 , while our results on the determinants of subjective economic welfare can be found in section 5. Section 6 offers some conclusions.

\section{Sources of bias in identifying welfare effects from subjective data}

Subjective welfare data are typucally in the form of self-reported positions on a ladder which has a natural ordering, such as from "poor" to "rich" or "very bad" to "very good". We doubt if responses to this type of question are prone to serious measurement error; there is no obvious reason why respondents would not tell you how they feel at the time. However, the literature in psychology has pointed to "mood variability" as a factor in self-rated welfare (Diener et al., 1999). Two equally happy people may have very different variances in their happiness over time, and self-rated wellbeing can then vary greatly according to the time of interview. (An example of such a transient effect is how a recent experience ended; see Fredrickson and Kahneman, 1993). While mood variability reduces the statistical fit with regressors related to longer-term determinants of welfare, it is not an obvious source of bias.

There are reasons to be concerned about bias. Aggregation is one. Individual income in a cross-section at one date may well be highly correlated with self-rated welfare across individuals, while at the same time aggregate economic growth results in little or no change in average self-rated welfare. This can happen if it is relative income that matters at the individual level — relative to (say) the mean income in the society as a whole - and if the economic growth is distribution neutral (incomes at all levels growing at the same rate). If inequality does not change much, or tends to increase with economic growth, then one can readily explain why economic growth does not translate into rising average happiness, without concluding that individual incomes are irrelevant to individual welfare.

Distributional effects can also arise from the data aggregation process. Subjective welfare questions are typically asked of individuals, whereas income measures are usually for 
households or even for large aggregates, such as nations. Then inequality within households (or countries) can influence the relationship between subjective welfare and average income. And this can hold even if subjective welfare does not depend directly on relative position. In particular, if individual subjective welfare is a concave function of income, then higher income inequality will lower average subjective welfare holding average income constant. ${ }^{8}$ Economic growth with rising inequality may entail little or no gain in average subjective welfare even when there is a strong income effect at the micro level.

Another concern is measurement error in reported incomes. The subjective wellbeing surveys used in much of the literature appear to have obtained "income" from just one or a small number of questions. For example, the German survey used by Winkelmann and Winkelmann (1998, p.14) obtains income from answers to a single question: "If everything is taken together, how high is the total monthly income of all household members at present?" The resulting estimates could deviate substantially from what one would get from a detailed household income and expenditure survey, with individual incomes identified by source, with imputations for income-in-kind. One then expects the income effect to be underestimated in most past studies, due to the usual attenuation bias. This expectation assumes a white noise measurement error in incomes; we return to this point, and consider possible biases in other coefficients arising from the structure of measurement errors.

Miss-specification of the relevant income variable can be a concern even with more detailed surveys. There is scope for debate at virtually every step in obtaining a measure of "income". There are issues about whether it should be income or expenditure, what should be included, how one should adjust for differences in household size, how cost-of-living deflators should be constructed and so on. The methods used in practice - even with elaborate surveys - need not accord well with subjective assessments. There may be

\footnotetext{
8 This follows straightforwardly from Jensen's inequality, and is known from the literature on measuring inequality (following Atkinson, 1970).
} 
differences in the time period over which income is measured versus the time period on which self perceptions of wellbeing are based. Past incomes can also matter, through savings. So too may expected future incomes (or determinants of these) matter, when either utility is not inter-temporally separable, or the time period over which subjective welfare is being assessed is longer than that over which income is measured. Defensible alternative methods of measurement may well yield a stronger correlation. ${ }^{9}$

There are also attributes of subjective data that need to be considered in assessing income and other effects. Precisely because it is "subjective", different people can have different personal notions of what a "high" or "low" level of subjective welfare means, and the differences may not be accountable in terms of readily observable data. ${ }^{10}$

One source of heterogeneity is personality. Some people seem to have been born happy, or have persistent personality traits that make them happy. There is evidence from psychological research that intrinsic, inter-temporarily stable, personality traits systematically influence reported wellbeing. In a meta-analysis of research in psychology, De Nerve and Cooper (1999) identify 137 personality traits correlated with subjective wellbeing, grouped under five commonly-used headings in psychology: "extraversion", "agreeableness", "conscientiousness", "neuroticism" or "emotional stability", and "openness to experience". These psychological traits are not normally measured in standard socio-economic surveys and, even if they were, including them as regressors would create concerns about their endogeneity. Identifying the causal effect of a personality trait on mean happiness (say)

\footnotetext{
9 Indeed, it has been argued that subjective welfare data can provide the extra information needed to calibrate the equivalence scales used in real income comparisons (van Praag, 1991; Kapteyn, 1994).

10 This is recognized in the literature on subjective wellbeing; for example, Veenhoven (1996, p.1) writes that ".the prefix 'subjective' means that criteria for judgement may vary from person to person". However, some researchers in this field have strongly defended the consistency and stability of the scales used (Diener et al., 1999):
} 
would seem problematic; it is hard to imagine a valid instrumental variable - correlated with observed personality traits but that does not influence happiness given personality.

Are these psychological factors in perceptions of wellbeing of concern in using such data to assess welfare effects? Of the 137 personality traits identified by De Nerve and Cooper, the strongest correlates with subjective wellbeing within the five categories mentioned above are:" esteem", "fear of intimacy" (negative), "interpersonal locus of control", "social emotionality", "social interest", "social tempo", "trust"; conscientiousness: “desire for control", "inhibition" (negative), "plasticity"; neuroticism: "distress" (negative), "emotional stability", "rebellious-distrustful" (negative), "repressive defensiveness" (negative), "social anxiety" (negative), "tension" (negative); openness to experience: "self-confidence", "selfrespect". These are differences in tastes which one would want to control for in making inter-personal comparisons of welfare for most purposes (such as for tax or welfare-policy making); the fact that a person is inhibited, rebellious or unconfident, would not normally constitute a case for favorable tax treatment. If these psychological factors happened to be uncorrelated with the other variables of interest then we would not need to control for them when measuring the welfare effect of unemployment, say. Explanatory power will be lower, but the latent psychological factors will not bias the results.

However, it is plausible that a number of the personality traits that raise self-rated welfare are also positively correlated with income and negatively correlated with unemployment. The above list of personality traits thought to promote a feeling of wellbeing overlaps considerably with the desirable things human resource managers are told to look for when interviewing job candidates (Darity and Goldsmith, 1996). This makes sense, since there is evidence that happy workers are more productive in various ways (Frank, 1985,

\footnotetext{
${ }^{11}$ We chose personality traits with a weighted mean correlation coefficient (across samples) of 0.30 or higher; the correlation is positive unless noted otherwise.
} 
reviews the evidence). For example, there is a large literature in psychology suggesting that various personality traits influence worker absenteeism (examples include Judge et al., 1997, Kivimaki et al., 1997, and Salgado, 1997); some of the traits identified overlap noticeably with those thought to influence subjective well-being, such as extraversion, conscientiousness and emotional stability (De Neve and Cooper, 1999). One can also conjecture that certain personality traits simultaneously promote happiness, but make survey respondents disinclined to say they are sick. Thus it can be argued that the income and health effects on subjective welfare will be overestimated, as will the absolute $\in$ ffect of unemployment (the actual effect will be less negative than the estimated effect).

One can also expect the income measurement error to be correlated with other variables of interest. For example, it is often conjectured that the rich tend to understate their incomes when asked by a stranger in an interview for some survey. (This is not implausible in Russia in the mid 1990s.) They are also less likely to be unemployed. Then the negative correlation between unemployment and subjective welfare could be due entirely to this structure of measurement errors; unemployment will appear to lower subjective wellbeing even if it has no real welfare effect beyond the loss of income. Similarly, if the time period over which incomes are measured is too short - and it is a longer-term income concept that drives self-assessments of welfare - we can expect unemployment and possibly other characteristics to be correlated with the difference between the two income measures. Unemployment might have a significant negative effect on subjective welfare at given current income simply because respondents naturally worry about future income too. That does not of course mean that leisure is undesirable, or that there are no adverse incentive effects of unemployment compensation. The otherwise remarkably high estimate of the level of unemployment benefits needed to create unemployment implied by the results in the literature (see, for example, Winkelmann and Winkelmann, 1998) could well reflect this 
structure of income measurement error, whereby the income effect is underestimated while the unemployment coefficient is overestimated.

The likely endogeneity of income to subjective welfare also clouds past efforts to test for the claim that it is income relative to some reference group - not absolute income - that matters to wellbeing. Stadt et al., (1985) and Clark and Oswald (1996) regress a subjective welfare indicator on both "own income" and an estimate of "comparison group income", namely the mean income of people with similar characteristics. The "comparison group" income is found to have a significant negative coefficient with own income entering positively; the authors conclude that it is relative income that matters to welfare. However, the significant effect of predicted income could also reflect a misspecification. Suppose that earnings are influenced by latent personality traits in subjective welfare via the effects of higher job satisfaction on labor turnover and disputes (as discussed in, for example Frank, 1985, and indeed Clark and Oswald, 1996). Then the significance of predicted income could be due solely to a correlation between own income and unobserved determinants of subjective welfare. ${ }^{12}$ Income endogeneity can generate spurious comparison group effects.

An important strand of the economics literature on subjective welfare has instead tested for effects on self-reported money metrics of welfare. Respondents are asked what income they need to secure stipulated welfare levels. An example is the "income evaluation question" (IEQ): "what after-tax income do you consider very bad, bad, sufficient, good, very

${ }^{12}$ Though this point applies to Stadt et al. as well, it is particularly clear in the case of the ClarkOswald test, since their "comparison group" income is the predicted income of a worker with the same characteristics from a first stage regression. Then its coefficient is just minus one times the coefficient on predicted residuals from the first-stage regression in a Wu-Hausman specification test (Hausman, 1978). Clark and Oswald note this possibility and try to address it using income estimated from a different data set as the comparison group income; this also has a negative and significant coefficient. (The same method of identifying comparison group effects is used by van de Stadt et al., 1985). However, this does not avoid the problem of income endogeneity; indeed, it may be even more affected by the problem, if this alternative test it is based on better instrumental variables. 
good". ${ }^{13}$ A special case is the minimum income question: "what income do you need to make ends meet?" The answers are then regressed on actual income and other variables, such as reference group income as in van de Stadt, et al., (1985).

The money metric approach can offer important insights (such as in setting a social subjective poverty line, as in Kapteyn et al., 1988; also see Pradhan and Ravallion, 1999), However, the estimated regressions do not in general provide unbiased estimates of the effects of socio-economic characteristics on subjective welfare. A simplified exposition of the method will make the identification problem obvious. Let $u$ denote subjective welfare, which is a function of income $y$, and a characteristic $x$, as $u=u(y, x)$, with $u_{y}>0$. The (unobserved and universally agreed) welfare level to make ends meet is $u^{*}$ which is a rising function of actual welfare, $u^{*}=g(u)$. The respondent's answer to the minimum income question is $y^{*}$ such that $u\left(y^{*}, x\right)=g[u(y, x)]$. Implicitly then, $y^{*}$ is a function of $y$ and $x$ with derivatives:

$$
\frac{\partial y^{*}}{\partial y}=\frac{g_{u}(u) u_{y}(y, x)}{u_{y}\left(y^{*}, x\right)} ; \frac{\partial y^{*}}{\partial x}=\frac{g_{u}(u) u_{x}(y, x)-u_{x}\left(y^{*}, x\right)}{u_{y}\left(y^{*}, x\right)}
$$

It is evident from (1) that the slopes of $y^{*}$ w.r.t. $y$ and $x$ (as estimated by regressing $y^{*}$ on $y$ and $x$ ) do not identify the corresponding marginal utilities. The marginal rate of substitution (MRS) between $y$ and $x\left(u_{x} / u_{y}\right)$ is identified in the special case in which the MRS does not vary with income (precisely, $\left.u_{x}(y, x) / u_{y}(y, x)=u_{x}\left(y^{*}, x\right) / u_{y}\left(y^{*}, x\right)\right)$; then:

$$
\frac{u_{x}(y, x)}{u_{y}(y, x)}=\frac{\partial y^{*} / \partial x}{\left(\partial y^{*} / \partial y\right)-1}
$$

In summary, both the cross-sectional micro evidence and the aggregate time--series evidence available could well have a hard time revealing the true welfare effects of changes in socioeconomic characteristics. The direction of bias is unclear on a priori grounds.

${ }_{13}$ The answers are often fitted to the normal distribution function, following Van Praag (1968). Seidl (1994) questions the theoretical basis for doing so, and Van Praag and Kapteyn (1994) defend it. 


\section{Setting and data}

In January 1992, the Russian government freed up prices on goods and services, which led to hyperinflation (1490\% in 1992; see World Bank, 1998), a sharp deterioration in the real value of savings, and a drop in real wages for the majority of the Russian population. A sharp drop in GNP was accompanied by an increase in unemployment, and income inequality. The income poverty rate rose sharply (Lokshin and Popkin, 1998). Rose and McAllister (1996) report subjective assessments of psychological wellbeing that suggest rising dissatisfaction in the $1990 \mathrm{~s}$.

Table 1 combines answers to a standard question on "satisfaction with life" from two different nationally representative surveys. The questions are not identical (we give the English translation of both), but they are similar. While only $13 \%$ of respondents to the 1991 survey said they were unsatisfied (including "not at all" or "completely" unsatisfied) this rose to $72 \%$ immediately after the economic reforms. Possibly the wording "less than satisfied" (in the 1992 and subsequent surveys) is somewhat less strong than "unsatisfied" (in the 1991 survey). This might account for some of the difference. However, looking at the distribution across the categories of potential responses, it appears from Table 1 that there was a sharp deterioration in subjective welfare.

Of course (following the observations made in the last section), these aggregate results do not imply that self-rated welfare is responsive to income changes at the micro level. Possibly self-rated welfare is driven entirely by relative income, and it is the rise in inequality in Russia that is driving these results. We next turn to micro panel data.

Since the pre- and post-reform data used in creating Table 1 are from different surveys, and interviewed different people, we cannot span the reforms. The post-reform data, however, are longitudinal, though there are two distinct panels, 1992 and 1993, and 1994 to 
1996. Between the latter two years there was a marked increase in the proportion of the sample in the least-satisfied category, and this is the period we will focus on:

We use the Russian Longitudinal Monitoring Survey (RLMS) for 1994 and $1996 .{ }^{14}$ RLMS is based on the first nationally representative sample of several thousand households across the Russian Federation. ${ }^{15}$ The RLMS was designed as a panel, and we can track 5,588 adults over the rounds for 1994 and 1996, slightly over 5,000 with complete data.

The survey included the following question: "Please imagine a 9-step ladder where on the bottom, the first step, stand the poorest people, and on the highest step, the ninth, stand the rich. On which step are you today?" We will call this the Economic Ladder Question (ELQ). The question does not presume that "income" is the relevant variable for defining who is "poor" and who is not, but leaves that up to the respondent. At the same time, by using the words "poor" and "rich" the question focuses on a more narrow concept of welfare than the questions often used in surveys, which refer to broader welfare concepts such as "happiness" or "satisfaction with life". It does not appear plausible to us that discrepancies between answers to the ELQ, as posed above, and an objective measure of real income reflect the fact that they are aiming to measure different things. The real income measure is after all calibrated (in theory at least) to a utility function which can be more or less broad. It is not unreasonable to assume that both are aiming to measure the same thing, which we will call "economic welfare".

All adults in the sampled households were asked the ELQ. We decided to condense the highest $7^{\text {th }}, 8^{\text {th }}$, and $9^{\text {th }}$ rungs into one, due to a small number of respondents who assigned

14 The sample was interviewed in 1995 though our main analysis confines attention to the 1994 and 1996 rounds.

15 A range of issues related to the sample design and collection of these data are explained in the documents found in the home page of the RLMS, where the data sets can also be obtained free; see http://www.cpc.unc.edu/projects/rlms/rlms_home.html. 
themselves to these rungs (only 28 of the 7,405 respondents put themselves in rung 8 and only 3 put themselves on rung 9). So we treat the data as a seven-rung ladder.

The income variable we use is total real monthly disposable household income (in June 1992 prices); this includes wages and salaries, social security, private transfers, income in-kind and from home production. To convert to real values we use well-established regionspecific poverty lines as deflators (Popkin et al., 1995).

As always, there are various sources of error in measured real incomes, in both the levels and changes over time. There are concerns about whether the variables in the deflators have been measured well, and weighted correctly. There is likely to be deliberate underreporting of certain components of income, which are not legal or for which tax was evaded. This will be less of a problem for the data from those households who depend more heavily on legal income sources, notably wages from a regular job and governmental transfers. As one check, we will redo our regressions on a subsample restricted to the 2000 adults living in households for whom reported income is at least $90 \%$ from wages, pensions, unemployment benefits, child benefits, other governmental transfers and/or stipends. Our expectation is that these income components will be measured more accurately, though there is undoubtedly some measurement error here too, if only because we are basing the calculation on reported incomes. This restricted sample cannot be considered representative.

We will also use expenditures, as well as incomes. The expenditure measure is comprehensive, including imputations for consumption in kind (such as from family farms or enterprises) as well as cash expenditures. Including expenditures can help compensate for certain types of income measurement error; for example, a household with illegal income is unlikely to report that income accurately, but it could well be better reflected in expenditures. It can also be argued that subjective welfare will depend more on long-run ("permanent") income, which will be better reflected in current expenditures than current incomes. 


\section{Some descriptive statistics}

Table 2 summarizes responses to the ELQ. The row and column totals give the number of respondents for each ladder rung. By exploiting the panel nature of the survey, we also give the numbers of respondents with each possible combination of responses. Thus one can use the table to see how muchmovement up and down the ladder there was. Comparing the column and row totals we find that there was an increase in the proportion of adults reporting that they are in the poorest few rungs, though there is not first-order dominance over the distribution. Taking the poorest two rungs to be the subjectively poor, the subjective poverty rate rose from $28.7 \%$ to $31.6 \%$.

These data suggest considerable transient subjective poverty. Of the 1,602 adults who said in 1994 that they were on the poorest two rungs, 757 put themselves on the third or higher rung in $1996 ; 47 \%$ of the subjectively poor by this definition escaped poverty within two years. However, they were all replaced. Of the 1,763 respondents on the poorest two rungs in 1996, 918 had been on the third or a higher rung two years earlier.

The panel nature of the RLMS allows us to see how answers to the ELQ changed over time for the same people, and compare this to the growth rates of income relative to the poverty line. As was evident in Table 2, there is considerable transient subjective poverty; almost half of those who were on the poorest two rungs in 1994 placed themselves on the third or a higher rung two years later, and slightly over half of those who were on the lowest two rungs in 1996 had been on the third or a higher rung in 1994. There is a similar degree of transient poverty when assessed by incomes relative to the poverty line. $43 \%$ of responding adults who lived in households with an income below the poverty line in 1994 had escaped poverty in 1996 , while $70 \%$ of the poor in 1996 had not been poor two years earlier. ${ }^{16}$

${ }^{16}$ These calculations are based on simple headcounts using the panel of adults. 3,027 were not poor in either year; 1,244 were not poor in 1994 but were in 1996; 411 were not poor in 1996 but were in 1994, and 537 were poor both years. If we use the number of people we find that 4,380 were not poor 
Are the changes in ladder positions correlated with changes in household incomes?

Table 3 looks at the relationship between changes in ladder positions and income growth. We compare the answers to the ELQ for 1996 with those given by the same individuals in 1994. We find that the average growth rates of real income tend to rise as the gain in ladder rungs rises. However, there is also a high variance in growth rates within each category. There are people reporting a substantial improvement in their subjective welfare amongst those experiencing the largest income drops, and similarly there are people reporting a large drop in their subjective welfare amongst those with large measured gains in income.

Table 3 suggests an association between changes in ladder positions over time and the growth rates in incomes relative to the poverty line. When we construct the contingency table, the Cramer V statistic is 0.0778 (Chi-square $=189$, which is significant at the 0.001 level). ${ }^{17}$ While average growth rates are appreciably higher for those who report that their economic welfare has improved, there is clearly a large dispersion in growth rates amongst those in any given category according to their self-reported ladder positions.

\section{A multivariate model of subjective welfare with latent heterogeneity}

Three key attributes of subjective welfare data have bearing on our econometric specification. Firstly, the data come in the form of ordered qualitative variables; we cannot assume that the difference between rungs 1 and 2 of the ladder (say) means the same in terms of welfare as the difference between 2 and 3. Secondly, drawing on the literature in psychology (section 2) we can expect that unobserved personality differences jointly influence observed socioeconomic characteristics and reported perceptions of wellbeing. Psychologists view these personality traits as inter-temporarily stable but variable between

in both 1994 and 1996;2,086 were not poor in 1994 but were poor in 1996; 674 were not poor in 1996 but were in 1994, and 1010 were poor in both years. The extent of transient poverty is similar.

17 Cramer's V statistic lies between zero and one and is a measure of association between any two categorical variables; for further discussion see Agresti (1984). 
people. And thirdly, social reference-group effects can entail that the level of a person's subjective welfare at given personal and household characteristics will vary over time.

The last point warrants elaboration. Suppose that the self-rated welfare of person $i$ at date $t, u_{i t}$, is a linear function of income relative to the mean $y_{i t} / m_{t}$ where the income of person $i$ at date $t=1,2$ is $y_{i t}$ with mean $m_{t}$ formed over all $i$ at $t$. We can write this relationship as linear utility function with time-varying parameters $u_{i t}=\mathrm{a}+\mathrm{b} y_{i t} / m_{t}=\mathrm{a}+\beta_{t} y_{i t}$ where $\beta_{t}=\mathrm{b} / m_{t}$. (If the model is $u_{i t}=\mathrm{a}+\mathrm{b} \log \left(y_{i t} / m_{t}\right)$ then the time varying parameter is the intercept.) This offers an alternative approach to allowing for reference group effects to those based on comparison group means, as found in the literature (section 2). It is, however, an inconclusive test, since accepting the null that the model's parameters do not vary over time could mean either that relativities do not matter (i.e., that only own income matters) or that mean income does not change over time.

Our econometric model incorporates these three features. The essential idea is simply to interpret the ELQ as an ordinal, categorical, summary of an unobserved continuous utility function containing an additive individual effect. By taking first differences over time in the utility function we can eliminate the individual effect and then apply an ordered probit to the changes in ladder rungs. ${ }^{18}$

Two limitations of our method should be noted: First, the method is only feasible with two observations over time, since only then is there a natural ordering of the changes in ladder rungs. Since one wants to allow for changing parameters over time, this is not unduly restrictive. Secondly, we only deal with one kind of endogeneity, namely the dependence of respondent characteristics on a latent time-invariant psychological effect. We do not deal with endogeneity with respect to mood effects or other time invariant unobservables.

18 Clark and Oswald (1994) also used an ordered probit in modeling subjective welfare data. However, they used ordered probit on levels not differences. Naturally, this does not avoid the concerns raised in section 2 about latent heterogeneity. 
To outline the method more formally, let the ladder have $R$ rungs, with $R>1$. The ladder position at date $t=1,2$ for person $i$ is denoted $L_{i t}$. This is determined by the value of the latent continuous variable, $u_{i t}$, which is a function of a vector of exogenous characteristics $x_{i t}$, the function relating $u_{i t}$ to $x_{i t}$ can be interpreted as an indirect utility function. We make the standard assumption that the fonction is static, in that $u_{i t-1}$ does not influence $u_{i t}$ given $x_{i t}$. However, we allow the utility function to vary between people at given $x_{i t}$. In particular, we allow for a latent time-invariant individual effect in $u_{i t}$; this is interpretable as an idiosyncratic taste shifter in the utility function arising from psychological differences.

We assume that the utility function is linear in parameters and that it contains an additive error term. This has two components. The first is a time-invariant individual effect, $\eta_{t}$, representing personality traits and any other sources of latent heterogeneity, and time invariant measurement errors; $\eta_{t}$ is assumed to be correlated with $x_{i t}$. The second error component is a normal i.i.d. innovation error, $\varepsilon_{t t}$, interpretable as the mood variability effects discussed in the psychology literature, under the assumption that these are orthogonal to $x_{i t}$. The latter assumption is crucial; while we have little practical choice, violations of this assumption due to correlations between mood effects and observed circumstances cannot be ruled out theoretically, and will bias our estimates. The model is then:

$$
u_{i t}=\beta_{t} \cdot x_{i t}+\eta_{t}+\varepsilon_{u}(t=1,2 ; i=1, n)
$$

Notice that the parameter vector $\beta_{t}$ varies over time, reflecting the changes in reference group income, as discussed above. Following standard practice in panel data econometrics (see, for example, Chamberlain, 1984, and Hsiao, 1986), the bias in an OLS estimate of (4) due to non-zero correlations between $x_{i t}$ and $\eta_{t}$ can be eliminated by taking differences over time: ${ }^{19}$

$$
\Delta u_{i t}=\beta_{t} \cdot \Delta x_{i t}+\Delta \beta_{t} \cdot x_{i t-1}+\Delta \varepsilon_{u t}
$$


where $\Delta u_{i t}=u_{i 2}-u_{i 1}$ is the change in subjective welfare for person $i, \Delta x_{i t}=x_{i 2}-x_{i 1}$ is the vector of changes over time in the explanatory variables and $\Delta \beta_{\imath}=\beta_{2}-\beta_{1}$ is the corresponding vector of changes over time in the parameters. Notice that the parameters are constant over time (so the second term on the RHS vanishes) if either the reference values do not change, or relative positions d 6 not matter, as discussed above.

However, in this context we cannot estimate (4) directly since we do not observe $\Delta u_{i t}$. But we do observe the changes in ladder position between $t-1$ to $t$. Since there are $R$ rungs, there are $2 R-1$ possible changes in ladder position (falling by $R-1$ rungs, $R-2$ rungs, and so on through to no change, then up to a $R-1$ rung increase). For sufficiently large $R$ one could treat this as a continuous variable. However, most subjective welfare questions only identify 3-10 rungs. So we treat this as a discrete (but ordered) variable.

Corresponding to the $2 R-1$ possible changes in ladder position one can define $2(R-1)$ cut off points in the $\Delta u_{i t}$ dimension, $c_{1}, c_{2}, \ldots, c_{2(R-1)}$, such that if $\Delta u_{i t}<c_{1}$ then that person will have fallen by the maximum number of rungs $R-1\left(\Delta L_{i t}=1-R\right)$ while someone for whom $c_{1}<\Delta u_{i t}<c_{2}$ will fall by $R-2$ rungs, and so on. Let $F$ denote the distribution function of $\Delta \varepsilon_{u t}$; the distribution is normal since $\varepsilon_{i t}$ is a normal i.i.d. process. We can then write down the following ordered probit model of the changes in ladder responses:

$$
\begin{gathered}
\operatorname{Pr}\left(\Delta L_{i t}=1-R\right)=F\left(c_{1}-\beta_{t} \cdot \Delta x_{i t}-\Delta \beta_{t} \cdot x_{i t-1}\right) \\
\operatorname{Pr}\left(\Delta L_{i t}=k-R\right)= \\
F\left(c_{k}-\beta_{t} . \Delta x_{i t}-\Delta \beta_{t} \cdot x_{i t-1}\right)-F\left(c_{k-1}-\beta_{t} \cdot \Delta x_{i t}-\Delta \beta_{t} \cdot x_{i t-1}\right) \quad(k=2,3, . ., 2 R-3) \\
\operatorname{Pr}\left(\Delta L_{i t}=R-1\right)=1-F\left(c_{2 R-1}-\beta_{t} \cdot \Delta x_{i t}-\Delta \beta_{t}, x_{i t-1}\right)
\end{gathered}
$$

The final identifying assumption is to normalize the variance of $\Delta \varepsilon_{u t}$ to unity (as is standard in ordered probits.) Thus we estimate the $\beta_{t}$ parameters in equation (3) up to any scalar.

${ }^{19}$ Or by taking deviations from time means, which is equivalent with two observations in time. 


\section{Estimation results}

If we use the log difference of income relative to the poverty line as the sole explanatory variable then we obtain an ordered probit regression coefficient of 0.0245 with a standard error of 0.004 (a t-ratio of 6.15). This is significant at the 0.0005 level. However, two observations are notable. First zero growth in income relative to the poverty line was still perceived to reduce subjective welfare (Table 3). Secondly, the bulk of the loglikelihood of the qualitative perceptions of welfare is left unexplained by income growth rates; the pseudo $R^{2}$ for the OP regression on the growth rate is only $0.0095 ;{ }^{20}$ there is clearly a lot more to changing perceptions of economic welfare than measured income growth rates.

We consider two sets of additional explanatory variables. The first includes those one would expect to be included in a measure of real income per equivalent single adult. Here we include a comprehensive set of demographic variables, as might be used to form an equivalence scale. The second set of variables are not normally included in a measure of real income, but might well be considered to influence economic welfare independently of income. Here we include a variety of individual characteristics, including age and marital status, and measures of health, education, employment and consumption. We also include geographic dummy variables; these eliminate variance due to unexplained locational effects, such as local public goods and reference groups effects. (Variables that do not vary over time naturally appear in the regression since their coefficients may change over time.)

Table 4 gives our estimates for the full sample and the sample restricted to those for whom wages and government transfers account for at least $90 \%$ of reported income. ${ }^{21}$ (As

\footnotetext{
${ }^{20}$ We use the normalized Aldrich-Nelson (1990) pseudo $R^{2}$ rather than that of McFadden (1974) which is known to have a sizable bias downwards for ordered probits with more than three categories (Veall and Zimmerman, 1996).

${ }^{21}$ The standard errors are corrected for clustering (given that there is typically more than one respondent per household), but this makes negligible difference.
} 
usual, one cannot directly compare the coefficient estimates for the two columns, given that variance of the inter-temporal difference in innovation errors need not be the same.)

The changes in log household income and expenditure (both per capita) are both highly significant, with roughly equal proportionate effects in the full sample, though income has a higher weight in the restricted sample. The expenditure variable could well be picking up income measurement error in the whole sample.

Beyond the per capita normalizations for income and expenditure, there is only weak evidence of demographic effects. People living in households with a higher proportion of female adults tended to say that their ladder rung had improved over time. Women tended to say they are worse off, and especially so for widows. However, neither effect is evident in the restricted sample, and so these effects may stem from income measurement errors.

The fact that $(\log )$ household size is insignificant controlling for income and expenditure per capita suggests that there is little or no economy of size in subjective welfare. This stands in marked contrast to cross-sectional results; in earlier work we found that selfrated welfare in Russia rises with family size, while income relative to the poverty line falls (Ravallion and Lokshin, 1998). We suspect that the cross-sectional results are contaminated by a bias arising from a tendency for intrinsically happier people to have larger families.

Those who became unemployed tended to say that they were worse off, even controlling for the loss of income. Our results from the full sample imply large monetary values of the subjective welfare loss from unemployment. From Table 4 (full sample) we can readily calculate that $\log$ household income and expenditure would have to increase by $0.292 /(0.102+0.109)=1.4$ to compensate for unemployment. (We assume that the savings rate is constant, so both income and expenditure increase by the same proportion. We hold individual income constant, but this variable has such a small coefficient that its effect on the 
calculation is negligible. ${ }^{22}$ ) This implies that a large unemployment benefit would be needed to attract a worker out of work. Consider again a worker choosing between staying employed (which is the only source of income for the household) and being unemployed and receiving unemployment benefits. Then the unemployment benefit level would have to be four $\left(=e^{1.4}\right)$ times higher than the wage to attract the worker out of work.

However, while our qualitative welfare effect of becoming unemployed is consistent with past results, three caveats emerge. Firstly, our quantitative estimate of the welfare cost of unemployment is far lower than the most comparable estimate in the literature, namely Winkelmann and Winkelmann (1998). Their coefficient on a dummy variable for unemployment is seven times their coefficient on log household income. Consider again a worker choosing between staying employed (the only source of income) and being unemployed and receiving unemployment benefits. Then if we accept the Winkelmann and Winkelmann regressions they imply that the unemployment benefit level would have to be $1096\left(=\mathrm{e}^{7}\right)$ times higher than the wage to attract the worker out of work!

Secondly, our estimation method allows us to test whether there is symmetry in the effect of employment, by separating the welfare impact of going from being employed to unemployed from that of a change in the opposite direction. Strikingly, we find that going from being unemployed to employed does not raise subjective welfare (Table 4). If you lose your job then getting it back does not even partially restore subjective welfare. This casts doubt on incentive interpretations of the employment effect on subjective welfare - notably its supposed implications for setting unemployment benefits. Unless there is sufficient income gain, just the availability of a job will not attract the unemployed back to work.

Thirdly, when we restrict the analysis to the sub-sample for which incomes are more reliably estimated, the unemployment coefficient is halved in size, and its $95 \%$ confidence

${ }^{22}$ Note that individual income is not logged (since there are many zeros). At the sample mean individual income for 1994, the regression coefficient for the full sample in Table 4 implies an 
interval now includes zero (Table 4). ${ }^{23}$ It might be conjectured that this is because fewer workers in this sub-sample become unemployed during the period. However, that does not seem to be the reason; the proportion of sampled adults who become unemployed is $3.7 \%$ in the restricted sample versus $4.1 \%$ in the full sample. A more plausible explanation is that the unemployment variable is pioking up time-varying income measurement error, as we discussed in section 2. Notice that, while unemployment drops out in the restricted model, individual income becomes significant. This is consistent with a non-trivial measurement error in individual incomes in the full sample, assuming that the income measurement error is negatively correlated with unemployment.

Turning to the health variables in our model, we find that worse health lowers subjective economic welfare. In the full sample, "health becoming very bad" has almost the same effect on subjective welfare as becoming unemployed. Income and expenditure would have to increase by $0.227 /(0.102+0.109)=1.1$ to compensate for health becoming "very bad". The effect of a perceived health improvement is not however significant. The health effect is equally significant in the restricted sample, and health improvements also emerge as significant to perceived economic welfare.

We find very little sign of significant base-year effects. Income in 1994 does not, for example, matter to the change in ladder position from 1994 to 1996 given other variables. Nonetheless, we can reject the null hypothesis that the initial values are jointly zero (the chisquare test is significant at the $4 \%$ level, in both the full sample and the restricted sample). However, the lack of significant effects of initial income or expenditure is not what one would expect if it is really relative income that matters, given that it is plausible that reference-group mean incomes have changed in this setting.

elasticity of 0.01 ; for the restricted sample, it is larger 0.05 .

${ }_{23}$ If we repeat the calculation of the (household and individual) income and expenditure gains needed to compensate for unemployment using the estimates from the restricted sample (at mean . 


\section{Conclusions}

At first sight, asking people how they feel about their own welfare, and matching the answers with their observed circumstances, offers hope of directly identifying otherwise illusive welfare effects. However, a number of potential biases cloud the inferences that can be drawn. There is likely to be an attenuation bias on the estimated income effect due to the poor income measures typically used in such studies. And there is almost certainly an endogeneity bias, due to a dependence of relevant individual characteristics on the latent personality traits that are known to influence self-rated welfare. The overall direction of bias in (say) the income effect on welfare is unclear on a priori grounds. With a high-quality longitudinal survey one can go some way toward dealing with these concerns, though even with very good income measurements (by industry standards) there remain concerns about time-varying measurement errors.

We have proposed an econometric model for subjective-qualitative welfare data that tries to take account of the main properties of such data that psychologists and others have pointed to. By treating the mood effects as normal and i.i.d., and the personality effects as additive and time-invariant, we can use an ordered probit regression to retrieve the mean welfare effects of changes in observed characteristics from reported changes over two survey dates in self-reported positions on a welfare ladder of any length.

On applying this method to panel data for Russia 1994-96, we find that some of the results widely reported in past studies of subjective wellbeing appear to be robust, but others do not. Household income is a highly significant predictor of self-rated welfare. Individual income is a far weaker predictor. Health shocks lower subjective economic welfare, at given values of other variables in the model, including incomes. The demographic effects found cross-sectional studies (notably of household size, at given income per capita) are not robust.

individual income), then we find that unemployment benefit level would only need to be $80 \%$ higher than the wage to attract the worker out of work. 
The large economy of household size in individual subjective welfare suggested by past work appears to reflect latent personality effects on the demographic characteristics of the respondent's household.

We find evidence of an income-compensated welfare cost of unemployment, but it is less strong and robust than past studies have suggested. In the full sample, it would take a large gain in current income to compensate for becoming unemployed. However, our results point to a number of qualifications on past findings about the welfare effects of unemployment. While becoming unemployed entails a large welfare loss, that loss is not restored when an unemployed person gets a job. This implies a permanent welfare loss from even transient unemployment. It also suggests that high unemployment benefits do not attract people out of work, but they do discourage a return to work. Also, the unemployment effect is not robust to restricting the sample to those for whom incomes are almost certainly better measured. There could well be a large bias in past estimates of the (income-compensated) welfare effect of unemployment, arising from the structure of income measurement errors.

It is plausible that becoming unemployed or sick generates a welfare loss, even if there is full replacement of the income loss. People naturally become less happy with their lives when such a shock occurs. But we doubt if this is being captured in answers to the economic ladder question we have studied; people are telling us that they feel significantly poorer now, given their current income, when they suffer a shock. The more plausible interpretation is that the current welfare loss arises from some combination of lower expected future incomes and more uncertain incomes, the latter arising from greater exposure to uninsured risk outside the formal employment sector. 


\section{References}

Agresti, A. (1984) Analysis of Ordinal Categorical Data. New York: John Wiley and Sons.

Aldrich, J., and Nelson, F., (1984) Linear Probability, Logit, and Probit Models, Sage University Press.

Argyle, M. (1987) The Psychologu of Happiness, London: Methuen.

Atkinson, Anthony B., (1970) "On the Measurement of Inequality", Journal of Economic Theory 2: 244-263.

Blanchflower, David G. (1996) "Youth Labor Markets in 23 Countries: A Comparison Using Micro Data", in D. Stern (ed.) School to Work Policies and Practices in Thirteen Countries. Cresskill: Hampton Press.

Blanchflower, David G., and Andrew J. Oswald (1997), “A Study of Labor Markets and Youth Unemployment in Eastern Europe", Warwick Economic Research Paper 499, Department of Economics, Warwick University.

Chamberlain, G., (1984) "Panel Data", in Z. Griliches and M.D. Intriligator (eds) Handbook of Econometrics, Volume 2, Amsterdam: North-Holland.

Clark, Andrew E., and Andrew J. Oswald (1994) "Unhappiness and Unemployment", Economic Journal 104: 648-59. , and (1996) "Satisfaction and Comparison Income", Journal of Public Economics 61: 359-381.

Darity, William Jr., and A.H. Goldsmith (1996), "Social Psychology, Unemployment and Macroeconomics", Journal of Economic Perspectives 10: 121-140.

De Neve, Kristina M., and Harris Cooper (1999) "The Happy Personality: A Meta Analysis of 137 Personality Traits of Subjective Wellbeing", Psychological Bulletin 125: 197 229.

Diener, Ed (1984) “Subjective Wellbeing”, Psychological Bulletin 93:542-575. 
Indicators Research 31: 103-157.

Diener, Ed, and Eunkook Suh (1997.) "Measuring Quality of Life: Economic, Social and Subjective Indicators", Social Indicators Research 40: 189-216.

Diener, Ed, Eunkook Suh, Richard.E. Lucas and Heifi L. Smith (1999) "Subjective Wellbeing: Three Decades of Progress", Psychological Bulletin 125: 276-302.

Easterlin, Richard A., (1974) "Does Economic Growth Improve the Human Lot? Some Empirical Evidence", in P.A. David and M.W. Rider (eds) Nations and Households in Economic Growth. Essays in Honor of Moses Abramovitz. New York: Academic Press.

(1995) "Will Raising the Incomes of all Increase the Happiness of all?" Journal of Economic Behavior and Organization 27: 35-47.

Frank, Robert H. (1985) Choosing the Right Pond: Human Behavior and the Quest for Status. New York: Oxford University Press.

Fredrickson, B.L., and D. Kahneman (1993) "Duration Neglect in Retrospective Evaluation of Affective Episodes", Journal of Personality and Social Psychology 65: 45-55.

Furnham, Adrian and Michael Argyle (1998) The Psychology of Money, London: Routledge. Hausman, J. (1978), "Specification Tests in Econometrics", Econometrica 46: 1251-1271. Hsiao, Cheng (1986) Analysis of Panel Data, Cambridge: Cambridge University Press. Judge, Timothy, Joseph J. Martocchio and Carl Thoresen (1997) "Five-Factor Model of Personality and Employee Absence", Journal of Applied Psychology 82(5):745-755. Kahneman, Daniel and Carol Varey (1991), "Notes on the Psychology of Utility". In Jon Elster and John E. Roemer (eds) Interpersonal Comparisons of Wellbeing, Cambridge: Cambridge University Press.

Kapteyn, Arie (1994) "The Measurement of Household Cost Functions. Revealed Preference 
Versus Subjective Measures", Journal of Population Economics 7: 333-350.

Kapteyn, Arie, Peter Kooreman, and Rob Willemse (1988) "Some Methodological Issues in the Implementation of Subjective Poverty Definitions", Journal of Human Resources 23: $222-242$.

Kivimaki, Mika, J. Vahtera, L. Thomson, A. Griffiths, T. Cox, and J. Pentti (1997) "Psychosocial Factors Predicting Employee Sickness Absence During Economic Decline", Journal of Applied Psychology 82(6): 858-872.

Lanjouw, Peter, and Martin Ravallion (1995) "Poverty and Household Size", Economic Journal 105: 1415-1434.

Lokshin, Michael and Barry M. Popkin (1998) "The Emerging Underclass in the Russian Federation", Economic Development and Cultural Change, forthcoming. Mangahas, Mahar (1995) "Self-Rated Poverty in the Philippines, 1981-1992", International Journal of Public Opinion Research 7: 40-55.

McCrae, R.R., and P.T. Costa (1991) "Adding Liebe and Arbeit: The Full Five Factor Model and Wellbeing", Personality and Social Psychology Bulletin 17: 227-232.

McFadden, Daniel (1974) "Conditional Logit Analysis of Qualitative Choice Behavior", in P. Zarembka (ed) Frontiers in Econometrics, New York: Academic Press.

Oswald, A.J., (1997) "Happiness and Economic Performance", Economic Journal 107: 18151831.

Plug, Erik, (1997), Leyden Welfare and Beyond, Tinbergen Institute Research Series, University of Amsterdam.

Popkin, Barry, A. Baturin, M. Mozhina, and T. Mroz, with assistance of A. Safronova, I., Dmintrichev, E. Glinskaya, M. Lokshin, (1995) "The Russian Federation Subsistence Level: the Development of Regional Food Basket and Other Methodological improvements", Chapel Hill: Carolina Population Center. 
Pradhan, Menno and Martin Ravallion (1999), "Measuring Poverty Using Qualitative Perceptions of Welfare", Review of Economics and Statistics, forthcoming. Ravallion, Martin and Michael Lokshin (1998), "Self-Rated Welfare", Policy Research Working Paper, World Bank, Washington DC.

Rose, Richard and Ian McAllister (1996), "Is Money the Measure of Welfare in Russia?", Review of Income and Wealth, 42(1): 76-90.

Runciman, W.G. (1966), Relative Deprivation and Social Justice. Routledge and Kegan Paul. Salgado, Jesus F. (1997), The Five Factor Model of Personality and Job Performance in the European Community" Journal of Applied Psychology 82(1):30-43.

Seidl, Christian (1994) "How Sensible is the Leyden Individual Welfare Function of Income?", European Economic Review 38: 1633-1659.

van de Stadt, Huib, Arie Kapteyn, and Sara van de Geer (1985) "The relativity of utility: Evidence from panel data", Review of Economics and Statistics 67: 179-187.

Van Praag, Bernard M.S. (1968) Individual Welfare Functions and Consumer Behavior, Amsterdam: North-Holland. (1991) "Ordinal and Cardinal Utility: An Integration of the Two Dimensions of the Welfare Concept", Journal of Econometrics 50: 69-89.

Van Praag, Bernard M.S. and Arie Kapteyn (1994) "How sensible is the Leyden individual welfare function of income? A Reply" European Economic Review 38 (9): 1817-1825

Veall, M., and Zimmerman, K., (1996) "Pseudo-R² measures for some common limited dependent variable models," Journal of Economic Surveys, Vol.10, No. 3:241-259.

Veenhoven, Ruut (1996) “Developments in Satisfaction Research", Social Indicators Research 37: 1-46.

Veenhoven, Ruut, with the assistance of Joop Ehrhardt, Monica Sie Dhian Ho and Astrid de 
Vries (1993) Happiness in Nations: Subjective Perceptions of Life in 56 Nations 1946-1992, Erasmus University, Rotterdam.

Winkelmann, Liliana and Rainer Winkelmann (1998) "Why Are the Unemployed So Unhappy" Evidence from Panel Data", Economica, 65: 1-15.

World Bank (1998) World Development Report. New York: Oxford University Press. 
Table 1: Satisfaction with life in Russia, 1991-1996

\begin{tabular}{lcccccc}
\hline$\%$ & $\begin{array}{c}\text { Pre- } \\
\text { reform }\end{array}$ & & & Post-reform & & \\
& 1991 & 1992 & 1993 & 1994 & 1995 & 1996 \\
\hline $\begin{array}{l}\text { Fully satisfied ("Completely } \\
\text { satisfied" in the 1991 survey) }\end{array}$ & 5 & 2 & 2 & 3 & 3 & 2 \\
$\begin{array}{l}\text { Rather satisfied } \\
\text { ("satisfied" in 1991) } \\
\text { Both yes and no (same) }\end{array}$ & 39 & 9 & 10 & 11 & 10 & 9 \\
$\begin{array}{l}\text { Less than satisfied } \\
\text { ("unsatisfied" in 1991) }\end{array}$ & 43 & 18 & 20 & 20 & 20 & 20 \\
$\begin{array}{l}\text { Not at all satisfied } \\
\text { ("completely unsatisfied" in 1991) }\end{array}$ & 11 & 40 & 36 & 41 & 37 & 37 \\
\hline Sample size & 2 & 32 & 32 & 24 & 30 & 31 \\
\hline
\end{tabular}

Sources: The 1991 survey is the General Social Survey of the European USSR, April-May 1991. The data and documentation are found on web site of The Inter-university Consortium for Political and Social Research: http://www.icpsr.umich.edu, ICPSR number: 6500. The other surveys are the Russian Longitudinal Monitoring Survey, which is described in section 3 of this paper. The sample for the latter changed in 1994. 
Table 2: Movements up and down the subjective welfare ladder, Russia 1994-96

\begin{tabular}{|c|c|c|c|c|c|c|c|c|c|}
\hline & \multicolumn{9}{|c|}{1996} \\
\hline & & 1 & 2 & 3 & 4 & 5 & 6 & $7+$ & $\begin{array}{r}\text { Total } \\
(\%) \\
\text { [cumm.\%] }\end{array}$ \\
\hline & 1 & 253 & 181 & 140 & 69 & 59 & 14 & 6 & $\begin{array}{r}722 \\
(12.92) \\
{[12.92]}\end{array}$ \\
\hline & 2 & 189 & 222 & 212 & 132 & 107 & 9 & 9 & $\begin{array}{r}880 \\
(15.75) \\
{[28.67]}\end{array}$ \\
\hline & 3 & 148 & 245 & 388 & 305 & 226 & 38 & 26 & $\begin{array}{r}1376 \\
(24.62) \\
{[53.29]}\end{array}$ \\
\hline \multirow[t]{7}{*}{1994} & 4 & 111 & 153 & 271 & 288 & 299 & 61 & 22 & $\begin{array}{r}1205 \\
(21.56) \\
{[74.85]}\end{array}$ \\
\hline & 5 & 95 & 114 & 214 & 254 & 326 & 71 & 24 & $\begin{array}{r}1098 \\
(19.65) \\
{[94.50]}\end{array}$ \\
\hline & 6 & 24 & 19 & 29 & 50 & 71 & 16 & 9 & $\begin{array}{r}218 \\
(3.90) \\
{[98.46]}\end{array}$ \\
\hline & $7+$ & 3 & 6 & 16 & 30 & 17 & 6 & 11 & $\begin{array}{r}89 \\
(1.59) \\
{[100.00]} \\
\end{array}$ \\
\hline & Total & 823 & 940 & 1270 & 1128 & 1105 & 215 & 107 & 5588 \\
\hline & $(\%)$ & $(14.73)$ & $(16.82)$ & $(22.73)$ & $(20.19)$ & $(19.77)$ & $(3.85)$ & (1.91) & $(100.00)$ \\
\hline & [cum.\%] & {$[14.73]$} & {$[31.55]$} & {$[54.28]$} & {$[74.47]$} & {$[94.24]$} & [98.09] & {$[100.00]$} & n.a. \\
\hline
\end{tabular}

Note: The number within each cell is the number of respondents from the 1994-96 panel with each combination of answers to what their economic welfare is on a nine rung ladder. (Rungs 7-9 aggregated because of small number of responses.) 
Table 3: Changes in subjective economic welfare versus real income

\begin{tabular}{|c|c|c|c|c|c|c|c|c|c|c|c|c|c|}
\hline \multirow{2}{*}{$\begin{array}{l}\text { Change in } \\
\text { subjective } \\
\text { welfare, } \\
1994-1996 \\
\end{array}$} & \multirow{2}{*}{$\begin{array}{l}\text { Number of } \\
\text { responses } \\
(\%)\end{array}$} & \multirow{2}{*}{$\begin{array}{l}\text { Mean } \\
\text { growth rate } \\
\text { of income } \\
\text { relative to } \\
\text { the poverty } \\
\text { line }(\%)\end{array}$} & \multicolumn{7}{|c|}{ Falling income relative to the poverty line ( $\%)$} & \multicolumn{4}{|c|}{ Rising income relative to the poverty line (\%) } \\
\hline & & & $-80+$ & $-80-60$ & $-60-40$ & $-40-20$ & $-20-0$ & $0-20$ & $+20-40$ & $+40-60$ & $+60-80$ & $+80-100$ & $+100+$ \\
\hline $\begin{array}{l}\text { Fall by } 3 \text { or } \\
\text { morc rungs }\end{array}$ & $\begin{array}{c}381 \\
(7.86)\end{array}$ & -21.91 & 87 & 56 & 60 & 27 & 52 & 19 & 14 & 17 & 9 & 6 & 34 \\
\hline $\begin{array}{l}\text { Fall by } 2 \\
\text { rungs }\end{array}$ & $\begin{array}{c}488 \\
(10.86)\end{array}$ & -2.91 & 91 & 79 & 71 & 37 & 66 & 29 & 26 & 19 & 12 & 9 & 49 \\
\hline $\begin{array}{l}\text { Fall by } 1 \\
\text { rung }\end{array}$ & $\begin{array}{c}884 \\
(18.23)\end{array}$ & -1.91 & 147 & 129 & 148 & 66 & 121 & 61 & 50 & 38 & 27 & -10 & 87 \\
\hline No change & $\begin{array}{c}1307 \\
(26.95)\end{array}$ & 15.46 & 167 & 169 & 212 & 92 & 176 & 125 & 79 & 64 & 42 & 21 & 160 \\
\hline $\begin{array}{l}\text { Increase by } \\
1 \text { rung }\end{array}$ & $\begin{array}{c}953 \\
(19.65)\end{array}$ & 22.95 & 104 & 115 & 107 & 85 & 134 & 98 & 74 & 40 & 32 & 34 & 130 \\
\hline $\begin{array}{l}\text { Increase by } \\
2 \text { rungs }\end{array}$ & $\begin{array}{c}517 \\
(10.66)\end{array}$ & 49.52 & 57 & 52 & 64 & 34 & 57 & 57 & 37 & 25 & 25 & 16 & 93 \\
\hline $\begin{array}{l}\text { Increase by } \\
3 \text { of more } \\
\text { rungs }\end{array}$ & $\begin{array}{l}320 \\
(6.60)\end{array}$ & 73.42 & 42 & 31 & 39 & 15 & 32 & 37 & 23 & 10 & 13 & 13 & 65 \\
\hline
\end{tabular}


Table 4: Ordered probits for the changes in subjective welfare

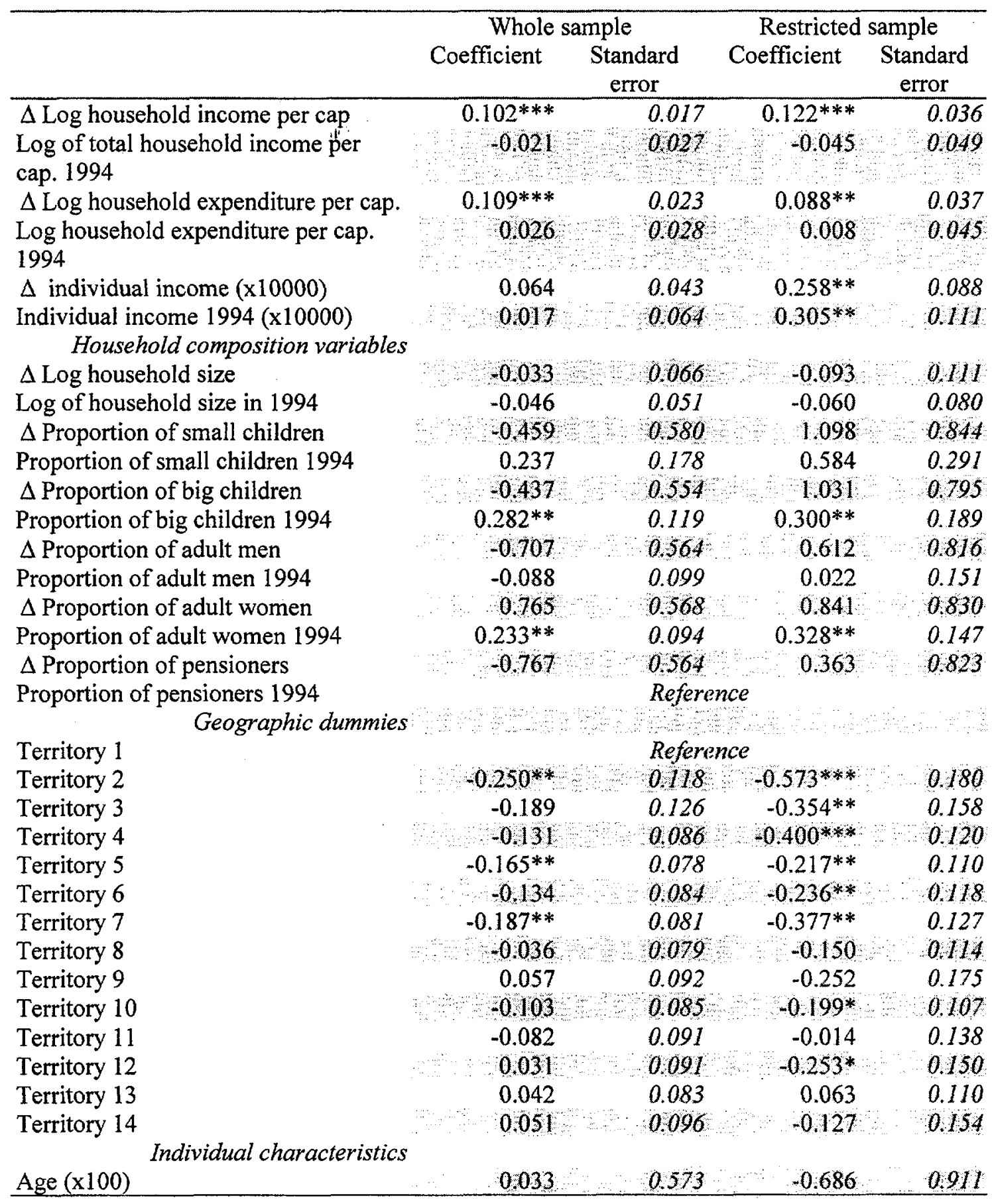


Table 4 continued

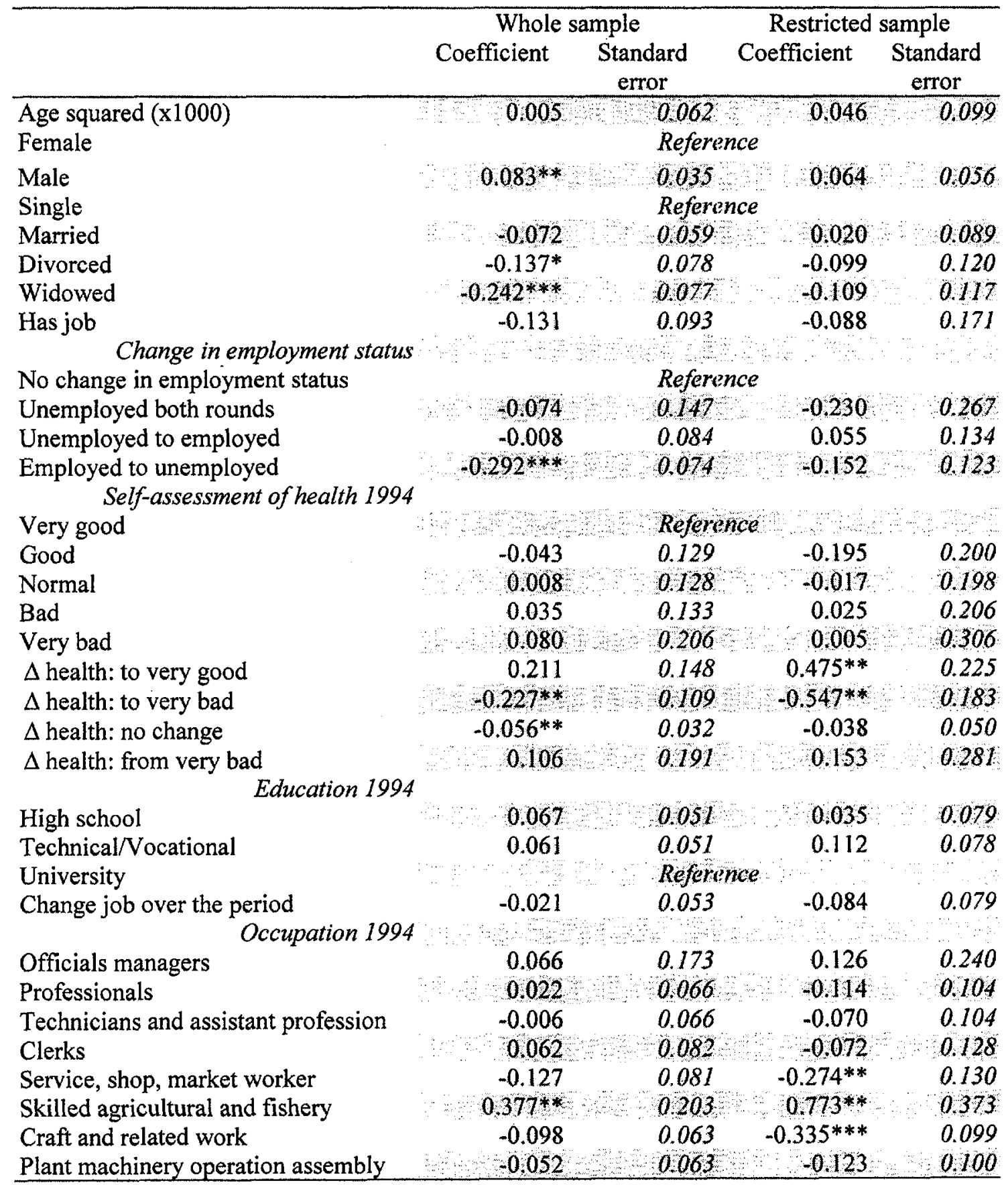


Table 4 continued

\begin{tabular}{lrrrrr}
\hline & $\begin{array}{c}\text { Whole sample } \\
\text { Coefficient }\end{array}$ & $\begin{array}{c}\text { Standard } \\
\text { error }\end{array}$ & $\begin{array}{c}\text { Restricted sample } \\
\text { Coefficient }\end{array}$ & $\begin{array}{c}\text { Standard } \\
\text { error }\end{array}$ \\
\hline Manual labor & $0.113^{*}$ & 0.069 & 0.136 & 0.112 \\
Armed force & -0.416 & 0.228 & -0.078 & 0.327 \\
& Ancillary parameters & & & & \\
$c 1$ & -3.499 & 0.360 & -3.969 & 0.575 \\
$c 2$ & -2.835 & 0.329 & -3.421 & 0.550 \\
$c 3$ & -2.180 & 0.324 & -2.741 & 0.543 \\
$c 4$ & -1.679 & 0.323 & -2.308 & 0.541 \\
$c 5$ & -1.160 & 0.322 & -1.786 & 0.541 \\
$c 6$ & -0.575 & 0.322 & -1.199 & 0.540 \\
$c 7$ & 0.139 & 0.322 & -0.439 & 0.540 \\
$c 8$ & 0.757 & 0.322 & 0.207 & 0.540 \\
$c 9$ & 1.342 & 0.323 & 0.798 & 0.540 \\
$c 10$ & 1.852 & 0.324 & 1.377 & 0.542 \\
$c 11$ & 2.415 & 0.329 & 1.872 & 0.549 \\
$c 12$ & 2.965 & 0.349 & 2.443 & 0.580 \\
\hline Number of observations & 5003 & & 2012 & \\
Pseudo-R2 & 0.152 & & 0.286 & \\
\hline
\end{tabular}

Note: ${ }^{*}$ is significant at $10 \%$ level; ${ }^{* *}$ at $5 \%$ level; ${ }^{* * *}$ at $1 \%$ level. 


\section{Policy Research Working Paper Series}

\begin{tabular}{|c|c|c|c|c|}
\hline & Title & Author & Date & $\begin{array}{l}\text { Contact } \\
\text { for paper }\end{array}$ \\
\hline WPS2277 & $\begin{array}{l}\text { Determinants of Bulgarian Brady } \\
\text { Bond Prices: An Empirical } \\
\text { Assessment }\end{array}$ & $\begin{array}{l}\text { Nina Budina } \\
\text { Tzvetan Mantchev }\end{array}$ & January 2000 & $\begin{array}{l}\text { N. Budina } \\
82045\end{array}$ \\
\hline WPS2278 & $\begin{array}{l}\text { Liquidity Constraints and Investment } \\
\text { in Transition Economies: The Case } \\
\text { of Bulgaria }\end{array}$ & $\begin{array}{l}\text { Nina Budina } \\
\text { Harry Garretsen }\end{array}$ & January 2000 & $\begin{array}{l}\text { N. Budina } \\
82045\end{array}$ \\
\hline WPS2279 & $\begin{array}{l}\text { Broad Roads in a Thin Country: } \\
\text { Infrastructure Concessions in Chile }\end{array}$ & $\begin{array}{l}\text { Andrés Gómez-Lobo } \\
\text { Sergio Hinojosa }\end{array}$ & January 2000 & $\begin{array}{l}\text { G. Chenet-Smith } \\
36370\end{array}$ \\
\hline WPS2280 & $\begin{array}{l}\text { Willingness to Pay for Air Quality } \\
\text { Improvements in Sofia, Bulgaria }\end{array}$ & $\begin{array}{l}\text { Hua Wang } \\
\text { Dale Whittington }\end{array}$ & January 2000 & $\begin{array}{l}\text { R. Yazigi } \\
37176\end{array}$ \\
\hline WPS2281 & $\begin{array}{l}\text { External Sustainability: A Stock } \\
\text { Equilibrium Perspective }\end{array}$ & $\begin{array}{l}\text { César Calderón } \\
\text { Norman Loayza }\end{array}$ & January 2000 & $\begin{array}{l}\text { H. Vargas } \\
38546\end{array}$ \\
\hline WPS2282 & Managing Fiscal Risk in Bulgaria & $\begin{array}{l}\text { Hana Polackova Brixi } \\
\text { Sergei Shatalov } \\
\text { Leila Zlaoui }\end{array}$ & January 2000 & $\begin{array}{l}\text { L. Zlaoui } \\
33100\end{array}$ \\
\hline WPS2283 & $\begin{array}{l}\text { New Tools and New Tests in } \\
\text { Comparative Political Economy: } \\
\text { The Database of Political Institutions }\end{array}$ & $\begin{array}{l}\text { Thorsten Beck } \\
\text { George Clarke } \\
\text { Alberto Groff } \\
\text { Philip Keefer } \\
\text { Patrick Walsh }\end{array}$ & February 2000 & $\begin{array}{l}\text { P. Sintim-Aboagye } \\
38526\end{array}$ \\
\hline WPS2284 & $\begin{array}{l}\text { The Use of Asset Management } \\
\text { Companies in the Resolution of } \\
\text { Banking Crises: Cross-Country } \\
\text { Experience }\end{array}$ & Daniela Klingebiel & February 2000 & $\begin{array}{l}\text { R. Vo } \\
33722\end{array}$ \\
\hline WPS2285 & $\begin{array}{l}\text { Industrial Environmental Performance } \\
\text { in China: The Impacts of Inspections }\end{array}$ & $\begin{array}{l}\text { Susmita Dasgupta } \\
\text { Benoît Laplante } \\
\text { Nlandu Mamingi } \\
\text { Hua Wang }\end{array}$ & February 2000 & $\begin{array}{l}\text { Y. D'Souza } \\
31449\end{array}$ \\
\hline WPS2286 & $\begin{array}{l}\text { Transparency, Liberalization, } \\
\text { and Banking Crises }\end{array}$ & $\begin{array}{l}\text { Gil Mehrez } \\
\text { Daniel Kaufmann }\end{array}$ & February 2000 & $\begin{array}{l}\text { D. Bouvet } \\
35818\end{array}$ \\
\hline WPS2287 & $\begin{array}{l}\text { The Vicious Circles of Control: } \\
\text { Regional Governments and Insiders } \\
\text { in Privatized Russian Enterprises }\end{array}$ & $\begin{array}{l}\text { Raj M. Desai } \\
\text { Itzhak Goldberg }\end{array}$ & February 2000 & $\begin{array}{l}\text { S. Cox } \\
36633\end{array}$ \\
\hline WPS2288 & $\begin{array}{l}\text { Ten Years of Transformation: } \\
\text { Macroeconomic Lessons }\end{array}$ & Charles Wyplosz & February 2000 & $\begin{array}{l}\text { M. Jandu } \\
33103\end{array}$ \\
\hline
\end{tabular}




\section{Policy Research Working Paper Series}

\section{Title}

WPS2289 Exchange Rate Overvaluation and and Trade Protection: Lessons from Experience

WPS2290 Decentralization and Corruption: Evidence across Countries

WPS2291 Incentives for Pollution Control: Regulation and Public Disclosure

WPS2292 Dividing the Spoils: Pensions, Privatization, and Reform in Russia's Transition

WPS2293 Should Capital Flows be Regulated? A Look at the Issues and Policies

WPS2294 Reforming the Urban Water System in Santiago, Chile

WPS2295 Resolving Bank Failures in Argentina: Recent Developments and Issues

WPS2296 An Ecological and Historical Perspective on Agricultural Development in Southeast Asia

WPS2297 Sources of Ethnic Inequality in Vietnam

WPS2298 Fiscal Deficits, Monetary Reform, and Inflation Stabilization in Romania

WPS2299 Household Savings in Transition Economies

WPS2300 Single Mothers in Russia: Household Strategies for Coping with Poverty
Author

Howard J. Shatz

David G. Tarr

Raymond Fisman

Roberta Gatti

Jérôme Foulon

Paul Lanoie

Benoît Laplante

Ethan B. Kapstein

Branko Milanovic

Roumeen Islam

Mary M. Shirley

L. Colin Xu

Ana Maria Zuluaga

Augusto de la Torre

Yujiro Hayami

Dominique van de Walle

Dileni Gunewardena

Nina Budina

Sweder van Wijnbergen

Cevdet Denizer

Holger C. Wolf

Yvonne Ying

Michael Lokshin

Kathleen Mullan Harris Barry Popkin
March 2000

\section{Date}

February 2000

February 2000

February 2000

March 2000

March 2000

March 2000

March 2000

March 2000

March 2000

March 2000

March 2000

33902
P. Sader

Contact for paper

L. Tabada 36896

E. Khine

37471

Y. D'Souza

31449

P. Sader 33902

R. Islam

32628

P. Sintim-Aboagye 38526

M. De Loayza 38902

P. Kokila 33716

H. Sladovich 37698

N. Budina 82045

A. Cubukcu 38449 